\title{
MANUSIA IDEAL DALAM PRESPEKTIF TASAWWUF \& FILSAFAT (STUDI KOMPERATIF PEMIKIRAN IBNU ARABY DAN NIETSCHE TENTANG MANUSIA)
}

\section{Ainul Fithriyah}

STAI Al-Azhar Menganti-Gresik ainulfithriyahg@gmail.com

\begin{abstract}
Abstrak
The variety of thoughts about the optimal attainment of human self and the satisfaction of human life is what may have made Arthur Schopenhauer (1788-1868) deny all worldly phenomena. He saw that the world was full of suffering. Humans, as the supreme product of the basic activities of the world, are in fact the most unfortunate creatures. Therefore, humans will be able to achieve happiness when they are able to kill passions and cravings. Studies on the optimal achievement of humans and the meaning of human life from the two figures above, are still important and beneficial to do. Because the concept of the ideal human being is a model and example for us that we can emulate or maybe we can make it happen if we feel fit and believe in the truth. But the question might arise, is it still relevant to study the thoughts of long-dead figures such as Ibn Arabi and Neitzsche? in the opinion of the author, the study of their thinking is still relevant. Because in their thoughts are contained eternal pearls, and because of the peculiarity of each thought. This is evident if we pay attention today, where the thoughts of the two figures are still the subject of study in various countries, both in the West and the East. The works that examine Nietzsche's thoughts about the Ubermensch man include the work of Chairul Arifin, entitled The will to power: Briedrich Nietzsche. This book discusses Nietzsche's views on human beings and his anti-theism. These two thoughts are then connected by the author of this book with Nietzsche's main thought, namely the will to power. And in one of its chapters, the book also examines the concept of Ubermensch Nietzsche. Another work that addresses Nietzsche and Nietzsche's main ideas, including Ubermensch in a separate chapter is Nietzsche by St Sunardi. Besides that, there are other books. Of the books mentioned above and others to the best of the author's knowledge, there has never been found a work that specifically compares Ibn Arabi's insan kamil concept and Nietzsche's Ubermensch concept.
\end{abstract}

Keywords: Ideal Human

\section{Abstark}

Ragam pemikiran tentang pencapaian optimal diri manusia dan kepuasan hidup manusia yang banyak inilah yang mungkin telah membuat Arthur Schopenhauer (1788-1868) menafikan segala fenomena duniawi. Ia melihat bahwa dunia penuh dengan penderitaan. Manusia sebagai produk tertinggi dari kegiatan dasar dunia ternyata merupakan makhluk yang paling malang. Oleh sebab itu, manusia akan dapat mencapai kebahagiaan bila telah mampu membunuh nafsu-nafsu dan keiginankeinginan. Kajian mengenai pencapaian optimal diri manusia dan kebermaknaan hidup manusia dari dua tokoh di atas, sampai saat ini rasanya masih tetap penting dan bermanfaat untuk dilakukan. Sebab konsep tentang manusia ideal merupakan model dan contoh bagi kita yang dapat kita teladani atau mungkin kita wujudkan bila kita merasa cocok dan meyakini kebenarannya. Tetapi mungkin akan muncul pertanyaan, apakah masih relevan mengkaji pemikiran tokoh-tokoh yang sudah lama tiada seperti Ibn Arabi dan Neitzsche? menurut pendapat penulis, kajian terhadap pemikiran mereka masih relevan untuk dilakukan. Sebab di dalam pemikiran mereka terkandung mutiara-mutiara abadi, serta karena kekhasan masing-masing pemikiran. Hal ini terbukti bila kita perhatikan saat ini, dimana pemikiran kedua tokoh tadi masih tetap menjadi bahan kajian di berbagai negara, baik di Barat maupun di Timur. Adapun karya-karya yang mengkaji pemikiran Nietzsche mengenai manusia Ubermensch diantaranya karya Chairul Arifin yang berjudul Kehendak untuk berkuasa: Briedrich Nietzsche. Buku ini membahas tentang pandangan Nietzsche mengenai manusia dan anti-teismenya, kedua pemikiran ini lalu dihubungkan penulis buku ini dengan pemikiran utama Nietzsche, yakni kehendak untuk berkuasa. Dan pada salah satu babnya, buku tersebut juga mengkaji konsep Ubermensch Nietzsche. Karya lain yang membahas Nietzsche dan pemikiran-pemikiran utama Nietzsche, termasuk juga Ubermensch dalam bab tersendiri adalah Nietzsche oleh St Sunardi. Disamping itu masih terdapat buku-buku lainnya. Dari buku-buku yang disebutkan di atas dan buku-buku lainnya sejauh pengetahuan penulis, belum pernah dijumpai sebuah karya yang membandingkan secara khusus konsep insan kamil Ibn Arabi dan konsep Ubermensch nya Nietzsche.

Kata Kunci: Manusia Ideal

Program Studi Pendidikan Guru Madrasah Ibtidaiyah

STAI Al-Azhar Menganti Gresik, Indonesia

Available online on: http://jurnal.stai-alazharmenganti.ac.id/index.php/ZAHRA 


\section{Pendahuluan}

Kajian tentang manusia merupakan obyek yang menarik dan tidak kunjung selesai untuk dibicarakan. Salah satu sebabnya adalah karena yang menjadi obyek dan subyek adalah manusia itu sendiri. Dari kajian-kajian tersebut telah tahir beragam disiplin ilmu; seperti ilmu ekonomi, ilmu budaya, ilmu psikologi, ilmu sosial, ilmu filsafat, dan lain sebagainya. Sekalipun demikian, anehnya kajian-kajian yang telah dilakukan tadi tetap tidak mampu memecahkan misteri manusia secara tuntas. (Charris. 1994) Salah satu aspek kajian yang menarik tentang manusia adalah menyangkut pencapaian optimal dirinya, kepuasan batinnya, serta kehidupannya yang bermakna. Sebab aspek ini berkaitan dengan bagian yang terdalam, terpenting dan mendasar dari hidupnya. Pandangan-pandangan tentang obyek di atas, sebenarnya telah muncul sejak dini. Kajian awal yang agak mendasar telah dilakukan oleh para filsuf Yunani klasik, seperti Pythagoras (wafat lebih kurang 600 SM), Plato (427-347 SM), dan Aristoteles (384-322 SM). Namun kajian-kajian tersebut masih belum memuaskan. Disamping faktor dari para filsuf, kajian tentang kesempurnaan manusia juga terdapat pada agama-agama kuno, misalnya dalam agama Hindu yang dapat kita jumpai dalam kitab Ramayana. sedangkan dalam agama Manu, kajian tentang kesempurnaan manusia disebut dengan Manusia Qadim.

Ragam pemikiran tentang pencapaian optimal diri manusia dan kepuasan hidup manusia yang banyak inilah yang mungkin telah membuat Arthur Schopenhauer (1788-1868) menafikan segala fenomena duniawi. Ia melihat bahwa dunia penuh dengan penderitaan. Manusia sebagai produk tertinggi dari kegiatan dasar dunia ternyata merupakan makhluk yang paling malang. Oleh sebab itu, manusia akan dapat mencapai kebahagiaan bila telah mampu membunuh nafsu-nafsu dan keiginan-keinginan. Demikianlah, pertarungan pemikiran manusia senantiasa melaju dan berkembang, namun pokok permasalahan ini tak kunjung selesai. Dari tradisi Islam, kajian mengenai masalah di atas mendapat respon yang positif dari kalangan sufi. Salah satu kajian yang cukup komprehensif dilakukan oleh Ibn Arabi (1165$1240 \mathrm{M}$ ), seorang sufi dan filsuf mistik ternama yang dianggap kontroversial di dunia Islam. Hal ini berkaitan dengan pemikirannya yang pantheistic, terutama yang tertuang di dalam konsep wahdat al-wujud nya. Ibn Arabi merumuskan pemikirannya tentang pencapaian optimal manusia di dalam konsep insan kamil atau manusia sempurna. Menurut Ibn Arabi, insan kamil adalah manusia yang secara sempurna memantulkan nama-nama dan sifat Tuhan dan telah mencapai martabat paling tinggi dalam kesadarannya, yakni telah menyadari sepenuhnya kesatuan esensialnya dengan Tuhan. (Harry, 1992) Dari tradisi filsafat Barat, 
muncul seorang filsuf eksistensialis yang juga mengkaji masalah ini, dia adalah Friedrich Nietzsche (1844-1900 M). Disamping seorang eksistensialis, Nietzsche adalah seorang pemikir revolusioner. Dengan lantang ia menyatakan kepada masyarakat bahwa Tuhan sudah mati, dan dengan matinya Tuhan, maka terbuka lah kesempatan bagi munculnya manusia super (Ubermensch), manusia yang dicita-citakan Nietzsche. Menurut Nietzsche, Ubermensch adalah manusia yang kembali ke semangat kekuasaan, yang telah bebas dari belenggu sistem nilai dan moralis lama serta secara bebas mewujudkan kehendak untuk berkuasa. Ia merupakan suatu kemungkinan optimal seseorang berdasarkan potensialitas kemanusiaannya.

Dalam rangka untuk semakin memperjelas pemahaman terhadap dua konsep tentang pencapaian optimal manusia yang dapat kita sebut sebagai konsep manusia ideal masingmasing tokoh, karena konsep itu berisi tentang manusia yang dicita-citakan mereka tersebut diatas dan untuk mendobrak tembok pemisah serta prasangka-prasangka antara tradisi Pemikiran Islam dengan tradisi Pemikiran Barat, maka perlu dilakukan perbandingan diantara kedua konsep tersebut. Di dalam perbandingan ini, sifat-sifat hakiki dalam kedua konsep tersebut dapat menjadi lebih jelas dan tajam. Hal ini karena sebuah perbandingan akan memaksa untuk dengan tegas menentukan kesamaan dan perbedaan yang terdapat di dalam sesuatu yang dibandingkan. Dan dengan perbandingan pula akan dapat diketahui kelemahan dan kelebihan masing-masing konsep.

Kajian mengenai pencapaian optimal diri manusia dan kebermaknaan hidup manusia dari dua tokoh di atas, sampai saat ini rasanya masih tetap penting dan bermanfaat untuk dilakukan. Sebab konsep tentang manusia ideal merupakan model dan contoh bagi kita yang dapat kita teladani atau mungkin kita wujudkan bila kita merasa cocok dan meyakini kebenarannya. Tetapi mungkin akan muncul pertanyaan, apakah masih relevan mengkaji pemikiran tokoh-tokoh yang sudah lama tiada seperti Ibn Arabi dan Neitzsche? menurut pendapat penulis, kajian terhadap pemikiran mereka masih relevan untuk dilakukan. Sebab di dalam pemikiran mereka terkandung mutiara-mutiara abadi, serta karena kekhasan masingmasing pemikiran. Hal ini terbukti bila kita perhatikan saat ini, dimana pemikiran kedua tokoh tadi masih tetap menjadi bahan kajian di berbagai negara, baik di Barat maupun di Timur.

\section{Metode Penelitian}


Dalam penelitian yang mengkaji mengenai konsep pemikiran tokoh, maka pendekatan yang dipakai adalah pendekatan historis, yang bermaksud untuk mengetahui proses munculnya konsep tersebut dari tokoh yang bersangkutan berdasarkan sejarah kehidupannya. (Ali yunasril, 1992) Sedangkan mengenai teknik pengumpulan data, hal tersebut dilaksanakan dengan cara mengumpulkan sumber data berupa buku-buku yang mengkaji masalah yang dibahas. Sumber data tersebut dibagi menjadi dua:

1. Primer, yaitu buku-buku yang merupakan karya dari tokoh yang dibahas. Data primer yang dipakai adalah: Fusus al-Hikam, karya lbn Arabi; Al-Futuhat al Makkiyah, karya Ibn Arabi; Thus Spoke Zarathustra, karya Nietzsche.

2. Sekunder, yang merupakan sumber pendukung, yang berupa buku-buku karya orang lain tentang tokoh yang sedang dibahas. Adapun data sekundernya, menggunakan buku-buku yang berkaitan dengan masalah yang dibahas.

Untuk melakukan analisa terhadap data yang telah terkumpul, maka sesuai dengan sifat penelitian ini, metode yang digunakan adalah metode komparatif. Metode ini digunakan untuk menemukan perbedaan dan persamaan diantara dua konsep yang dibahas. Namun sebelumnya dipergunakan metode deskriptif untuk menggambarkan konsep yang akan dibandingkan. Disamping itu, metode induktif dan deduktif kadang-kadang digunakan di akhir pembahasan sebuah sub bab untuk memperjelas atau pun menyimpulkan hal yang selesai dibahas.

\section{Hasil Penelitian}

Dari kajian tentang cara menjadi manusia ideal, nampak adanya perbedaan yang sangat besar di antara keduanya bagi Ibn Arabi, untuk menjadi manusia ideal, seseorang harus mendekatkan dirinya kepada Tuhan dan berusaha untuk dapat berhubungan langsung dengan Nya Berlawanan dengan itu, bagi Nietzsche, untuk menjadi manusia ideal, seseorang harus terlebih dahulu "membunuh" Tuhan agar tidak ada penghalang baginya untuk merealisasikan kehendak untuk berkuasanya, setelah itu baru dapat dilaksanakan sublimasi. (Friedrich, 1975) Dalam pandangan filsafat eksistensi, cara menjadi manusia menurut Ibn Arabi mengarah kepada penghilangan eksistensi manusia, karena ingin menampakkan eksistensi Tuhan. Hal ini karena bagi Ibn Arabi, manusia dan alam semesta seluruhnya tidak mempunyai wujud. Wujud mereka adalah pinjaman dari Tuhan, satu-satunya wujud yang hakiki. Di samping itu, tujuan diciptakannya manusia dan alam adalah untuk menampakkan kesempurnaan Tuhan. Sedangkan cara menjadi manusia ideal menurut Nietzsche, mengarah kepada usaha untuk menegaskan eksistensi manusia. Bahkan karena dianggap mengancam eksistensi manusia, maka Tuhan pun harus "disingkirkan" dari dunia ini. Dengan tidak adanya Tuhan, maka terbukalah kesempatan bagi manusia untuk menjulangkan eksistensinya setinggi mungkin. (Hardiman, 1992) Nampaknya pandangan Nietzsche yang demikian inilah yang membuat para penulis memasukkan dia sebagai figur filsuf eksistensialisme. Pada dasarnya, insan kamil dapat menduduki kedua jabatan 
(khalifah) itu sekaligus, seperti halnya nabi Daud as. yang memegang kedua jabatan itu sekaligus. Senada dengan pandangan Nietzsche diatas, dalam hal ini Ibn Arabi bahkan memberikan kedudukan yang lebih penting lagi kepada manusia ideal. Menurutnya, manusia ideal (Insan kamil) juga memiliki dua kedudukan.

1. Sebagai khalifah (wakil) Tuhan dimuka bumi.

Dalam hal ini manusia ideal dianggap merupakan sebab muncul dan terpeliharanya alam semesta ini. Artinya, tanpa adanya manusia ideal, maka alam semesta beserta isinya akan lenyap. Hal ini karena tujuan penciptaan alam semesta, yaitu agar alam dapat memanifestasikan nama-nama dan sifat-sifat Tuhan secara sempurna, tidak dapat terpenuhi selain pada diri manusia ideal. Sebagai wakil Tuhan manusia ideal juga berfungsi melestarikan masyarakat dengan cara menciptakan kemakmuran, keadilan, serta ketentraman didalamnya. Konsep khalifah (wakil) Tuhan ini kalau ditelusuri nampaknya diambil oleh Ibn Arabi dari konsep Islam tentang manusia, yang pada satu sisi menekankan ketinggian manusia (yakni sebagai khalifah Nya) dan di sisi lain menekankan kerendahan manusia (sebagai abdi Nya). Kedua sisi ini bersama sama membentuk sifat fundamental manusia. (Nashr, 1994)

2. Manusia ideal(insan kamil) berkedudukan sebagai qutb(wali tertinggi) yang dikaruniai pengetahuan esoterik('ilm al-ladunni)

yaitu sejenis pengetahuan yang merupakan persepsi langsung terhadap kebenaran sehingga hasilnya pun sangat meyakinkan. Dengan demikian, manusia ideal dipandang sebagai sumber ilmu pengetahuan yang benar. Disamping berkedudukan sebagai khalifah, Insan kamil juga dipandang sebagai orang yang mendapat pengetahuan esoterik yang oleh Ibn Arabi disebut juga pengetahuan rahasia ( ilm al-asrar) atau pengetahuan kudus ( ilm alladunni) yaitu suatu bentuk pengetahuan tertinggi yang dapat dicapai manusia selain wahyu. Ia merupakan persepsi langsung terhadap kebenaran, sehingga hasilnya pun diyakini sepenuhnya. Pengetahuan ini merupakan karunia dari Tuhan setelah seseorang menempuh penyucian rohani. Sebenarnya sumber pengetahuan esoterik itu berada dalam diri manusia, tetapi untuk mencapainya seseorang harus telah menyadari jati dirinya. Orang yang telah menyadari jati dirinya itulah insan kamil, yang dipandang sebagai wali tertinggi atau qutb (paros). Dalam struktur hirarki spiritual sufi, qutb dipandang sebagai pimpinan tertinggi dari para wali. Ia hanya satu orang dalam setiap jaman. Selain itu ia dipandang sebagai pemegang jabatan khalifah, Diantara mereka adalah: khulafa' al-Rasyidin (Abu Bakar, Umar, Usman, dan Ali), Hasan Ibn Ali, 'Umar ibn Abdul 'Aziz, Abu Yazid al-Bustami, dan lain-lain.

Dari kajian diatas dapat disimpulkan bahwa insan kamil mempunyai dua kedudukan: sebagai khalifah (wakil) Allah dimuka bumi, dan sebagai wali tertinggi atau qutb yang memiliki pengetahuan esoteris. 
Berkaitan dengan kedudukan yang insan kamil dipandang sebagai penyebab adanya dan lestarinya alam, sebab dia adalah cermin yang paling sempurna citra (gambar) Ilahi. Sedangkan sebagai wali tertinggi, insan kamil dipandang sebagai sumber pengetahuan esoterik.

Pemikiran Nietzsche tentang manusia adalah merupakan reaksi terhadap pandangan agama Kristen tentang hidup dan manusia, yang menurut Nietzsche telah merendahkan derajat manusia: hidup ini adalah sesuatu yang tidak berharga sama sekali, manusia adalah mahluk yang berdosa, yang lemah itu harus dilindungi dan dikasihi, dan lain-lain. (Franz Magnis, 1997) Hal-hal inilah yang sangat dibenci Nietzsche. Menurut Nietzsche, manusia adalah mahluk yang masih belum selesai. Ia adalah proses yang tiada henti-henti nya untuk meraih sebuah tujuan. Nietzsche menggambarkan posisi manusia ini sebagai tali yang terentang diantara binatang dan Ubermensch, tali yang terentang di atas jurang. Dengan demikian tujuan hidup manusia adalah Ubermensch, yang secara terus menerus hendak ia realisasikan dalam hidupnya, sebab manusia memiliki potensi untuk mengatasi diri dan menentukan tujuan yang hanya dapat direalisasikan olah dirinya. sendiri. Dan dengan kedua hal inilah manusia mampu mewujudkan Ubermensch. Sebagai sesuatu yang ingin dicapai oleh manusia, Ubermensch diciptakan sendiri oleh manusia berdasarkan potensi (dorongan-dorongan hidup) yang dimiliki manusia, demikian juga cara mewujudkannya berdasarkan potensi-potensi yang dimilikinya. Curt Friedlin merumuskan bahwa Ubermensch itu merupakan kemungkinan optimal seseorang di waktu sekarang, dan bukan tingkat perkembangan yang berada jauh di depan yang hanya dirumuskan secara rasional.

Seperti pemikiran Ibn Arabi dan Nietzsche tentang konsep manusia ideal mereka Untuk mendapatkan gambaran yang kongkrit, maka yang akan dibandingkan adalah segi-segi perbedaan dan persamaan yang ada di dalam kedua konsep tersebut. Adapun aspek-aspek yang akan dibandingkan meliputi: dasar pemikiran konsep manusia ideal, pengertian manusia ideal, potensi manusia untuk menjadi manusia ideal, cara menjadi manusia ideal, kedudukan manusia ideal, dan personifikasi manusia ideal. Pemberian kedudukan yang sangat penting oleh Nietzsche dan Ibn Arabi kepada manusia ideal nampaknya dimaksudkan untuk menunjukkan betapa pentingnya arti manusia ideal bagi manusia dan dunia, dengan begitu akan memberi rangsangan bagi kita agar berusaha mewujudkannya. Disamping persamaan tersebut, pembahasan diatas juga menunjukkan adanya titik perbedaan yang cukup besar. Dalam manusia idealnya Nietzsche, kedudukan yang penting tersebut diraih dengan "membunuh Tuhan". karena baginya, Tuhan adalah hasil khayalan manusia yang lemah, yang akan menghalangi dirinya mengekspresikan kehendak untuk berkuasa secara maksimal. Sementara itu, manusia idealnya Ibn Arabi mendapatkan kedudukan tersebut setelah ia berhasil merealisasikan kesempurnaan Tuhan, dan ia merasa bahwa yang ada hanya wujud Tuhan. Untuk dapat mengenal manusia ideal, terdapat dua cara yang dapat digunakan yaitu dengan melihat rumusan manusia ideal, dan dengan cara melihat individu-individu nyata yang telah merealisasikan rumusan 
tersebut. ${ }^{1}$ Setelah rumusan tentang manusia ideal menurut Ibn Arabi dan Nietzsche kita bahas, kini saatnya kita lihat aktualisasi rumusan-rumusan tentang manusia ideal tadi dalam diri individu-individu manusia.

Berdasarkan data-data tentang personifikasi manusia ideal, dapat diketahui bahwa terdapat perbedaan antara Ibn Arabi dan Nietzsche mengenai masalah tersebut. Dalam pandangan Ibn Arabi, konsepnya tentang manusia ideal bukanlah sebuah konsep yang utopis, sebab rumusan manusia idealnya telah terwujud secara nyata Mereka yang telah mewujudkan konsep ini adalah para nabi serta para. wali, dan mencapai perwujudan yang paling tinggi pada diri Nabi Muhammad saw. Terkait dengan fungsi manusia ideal sebagai pemelihara alam semesta, dapat dikatakan bahwa sejak zaman nabi Adam as. sampai zaman akhir nanti, di dunia ini akan senantiasa ada manusia ideal. Sebab Tuhan (Allah) akan tetap memelihara alam semesta, jika Ia masih menemukan mahluk yang mampu memanifestasikan nama-nama dan sifat-sifat Nya secara sempurna. (Julian, 1992) Dengan berakhirnya kenabian pada diri nabi Muhammad saw., berarti manusia ideal sesudahnya dan sampai zaman akhir nanti hanya terwujud pada diri para wali saja yang sekaligus seorang sufi, karena hanya pada diri para nabi dan diri merekalah manusia ideal terwujud secara kongkrit. Berbeda dengan Ibn Arabi, dalam pandangan Nietzsche, rumusan manusia ideal itu masih belum terwujud dalam diri seorang manusia pun, setidaknya sampai ia meninggal dunia. Sejalan dengan pendapat ini, seorang pemerhati pemikiran Nietzsche yang juga seorang rohaniawan Katolik, Copleston S.J. bahkan mengatakan bahwa manusia idealnya Nietzsche itu adalah manusia masa depan, sebuah species baru yang belum pernah terwujud. Memang Nietzsche dalam karya karyanya sering menyebut beberapa tokoh yang dikaguminya, seperti Goethe, Napoleon dan Cesar Borgia. Namun bagi Nietzsche, mereka bukanlah manusia ideal. Mereka hanyalah orang-orang yang baru melihat manusia ideal, dan belum sampai merealisasikannya. (William C.,1989)

Perbedaan mengenai personifikasi manusia ideal, menimbulkan beberapa akibat. Diantaranya adalah, konsep manusia idealnya Ibn Arabi dapat dipahami dan dimengerti dengan lebih jelas dari pada konsep manusia idealnya Nietzsche. Hal ini terutama karena dengan terwujudnya rumusan manusia ideal dalam diri individu secara kongkrit, maka unsur-unsur yang kurang jelas dari konsep manusia ideal tersebut akan menjadi jelas. Disamping itu, betapapun jelas dan lengkapnya sebuah konsep, nampaknya akan tetap ada yang kurang, kecuali konsep tersebut telah teraplikasi dalam kenyataan. Apalagi jika kita perhatikan rumusan tentang manusia ideal yang diberikan Ibn Arabi dan Nietzsche sebelumnya, ternyata sebagian besar hanya berupa gambaran umum tentang manusia ideal. Akibat lain dari perbedaan mengenai personifikasi manusia ideal diatas adalah timbulnya anggapan bahwa konsep manusia idealnya Nietzsche terlalu ideal, sebab belum pernah ada manusia yang mampu mewujudkannya. Senada dengan anggapan ini, Copleston menyatakan bahwa manusia idealnya Nietzsche itu hanyalah sebuah mitos, tujuan bagi kehendak. Lebih jauh lagi, Chairul Arifin

\footnotetext{
${ }^{1}$ Muthahari, Manusia, 1-2
} 
mengatakan jika gambaran manusia ideal Nietzsche tidak dirubah maka ia tidak akan terwujud. Sehingga disimpulkan bahwa Ubermensch adalah manusia yang mampu merealisasikan kehendak untuk berkuasa yang berada di dalam dirinya secara maksimal berdasarkan potensi-potensi yang dimilikinya. (Arifin, Chairul, 1986)

\section{Simpulan}

Dalam pandangan Ibn Arabi, manusia ideal adalah manusia yang mampu memanifestasikan secara sempurna nama-nama dan sifat-sifat Tuhan (Allah) dalam dirinya, dan ia telah menyadari sepenuhnya kesatuan hakekatnya dengan Tuhan. Manusia seperti inilah yang disebut insan kamil oleh Ibn Arabi. Konsep insan kamil ini bertolak dari doktrin wahdat al-wujud yang berpandangan bahwa seluruh realitas atau wujud yang ada hanya mempunyai satu realitas, realitas tunggal itu adalah Allah. Adapun alam semesta yang serba ganda ini adalah wadah tajalli (penampakan diri) nama- nama dan sifat-sifat Nya. (1) Menurut Ibn Arabi setiap manusia secara potensial mempunyai kemampuan untuk mencerminkan kesempurnaan Tuhan secara sempurna dan utuh. Namun dalam kenyataannya hanya manusia tertentu saja yang mampu mewujudkan hal tersebut, yaitu insan kamil. Untuk bisa menjadi insan kamil seseorang harus berusaha berakhlak dengan akhlak Allah. Hal ini ditempuh melalui jalan tasawuf; dengan cara melatih rohani manusia melalui bermacam-macam ibadah serta kontemplasi yang harus sesuai dengan ajaran Islam. Dalam latihan rohani ini, seseorang harus menempuh maqamat (tingkat-tingkat kerohanian) yang berjumlah enam puluh tingkat. Karena insan kamil memiliki beberapa kelebihan dibanding mahluk-mahluk lain, Tuhan kemudian mengangkatnya sebagai wakil Nya di bumi. Sebagai wakil (secara maknawi dan dahiri), insan kamil dianggap sebagai penyebab muncul dan terpeliharanya alam semesta serta pelestari masyarakat. Disamping itu insan kamil juga berkedudukan sebagai qutb (wali tertinggi) yang mendapatkan pengetahuan yang sangat meyakinkan kebenarannya, yaitu al- `ilm al-ladunni. Bagi Ibn Arabi insan kamil sudah ada sejak nabi Adam as. dan akan tetap ada sampai hari akhir nanti. Mereka itu adalah para nabi dan para wali, dan mencapai perwujudannya yang paling sempurna dalam diri nabi Muhammad saw. (2) Sedangkan menurut Nietzsche, manusia ideal adalah Ubermensch, yaitu manusia yang mampu mencapai tingkatan tertinggi dari kemungkinan-kemungkinan dirinya sesuai dengan potensi (dorongandorongan hidup) yang dimilikinya, berdasarkan prinsip kehendak untuk berkuasa. Konsep Ubermensch ini bertolak dari prinsip kehendak untuk berkuasa. Menurut prinsip ini, hidup pada hakekatnya adalah kehendak untuk berkuasa, tujuan hidup adalah untuk menjadi lebih berkuasa. Dibandingkan dengan mahluk hidup yang lain manusia mempunyai kelebihan sehingga dia dapat meningkatkan kehendak untuk berkuasa secara optimal. Walaupun secara potensial setiap manusia mampu meningkatkan kehendak untuk berkuasa secara optimal, tetapi dalam kenyataan hanya manusia tertentu saja yang bisa mewujudkannya, yaitu Ubermensch. Untuk dapat menjadi Ubermensch, pertama-tama seseorang dituntut untuk mengakui bahwa Tuhan telah mati, bersikap 
afirmatif terhadap hidup, serta menyadari bahwa manusia adalah proses. Kemudian dia juga harus mampu mengendalikan dorongan-dorongan hidupnya, dan mengarahkannya kedalam tindakantindakan yang dapat meningkatkan kehendak untuk berkuasanya dan sekaligus dapat diterima masyarakat, hal inilah yang disebut sublimasi. Dalam kaitannya dengan manusia dan dunia, Ubermensch memiliki peran yang penting, yaitu sebagai tujuan hidup manusia dan sebagai sarana untuk memaknai (menilai) manusia dan dunia Bagi Nietzsche, setidaknya sampai ia mati, nampaknya Ubermensch ini belum pernah terwujud dalam diri individu-individu manusia.

Dari konsep manusia ideal menurut Ibn Arabi dan Nietzsche tersebut, ditemukan beberapa perbedaan dan persamaan. Dan ternyata perbedaannya sangat besar dibandingkan dengan persamaannya, bahkan dalam beberapa aspek berlawanan satu sama lain: (1) Perbedaan antara keduanya meliputi: aspek dasar pemikiran konsep manusia ideal; berupa hakekat realitas, dan corak dasar pemikiran tersebut. Aspek yang lain adalah dasar penetapan potensi manusia menjadi manusia ideal, aspek personifikasi manusia ideal, aspek pengertian manusia ideal, aspek cara menjadi manusia ideal, dan aspek kedudukan manusia ideal; berupa cara mendapatkan kedudukan tersebut. Dalam tiga aspek terakhir pemikiran Ibn Arabi dan Nietzsche bertentangan satu sama lain. (2) Persamaan diantara kedua konsep tersebut dapat dikatakan sedikit dan tidak begitu penting. Persamaan tersebut berupa : aspek dasar pemikiran, yakni keduanya merupakan pengikut monisme. Aspek kedudukan manusia ideal, dan potensi manusia untuk menjadi manusia ideal.

\section{Daftar Pustaka}

Ali, Yunasril. (1992). Manusia Citra Ilahi: Pengembangan Konsep Insan Kamil Ibn Arabi oleh alJilli. Jakarta: Paramadina.

Arifin, Chairul. (1986). Kehendak Untuk Berkuasa. Jakarta: Erlangga.

Asmaran, As. (1996). Pengantar Studi Tasawuf . Jakarta: PT. Raja Crafindo Persada.

Bakker, Anton dan Zubair, Achmad Charris. (1994). Metode Penelitian Filsafat. Yogyakarta: Kanisius.

Baldick, Julian. (1992). Mystical Islam: An Introduction to Sufism. London: I.B. Tauris dan Co. L

Chittick, William C. (1989). The Sufi Path of Knowledge: Ibn al-Arabi's Metaphysics of Imagination. Albany: State University of New York Press.

Copleston, Friedrich. (1975). Friedrich Nietzsche: Philosopher of Culture. London: Search Press.

Delfgaauw, Bernard D. Sejarah Ringkas Filsafat Barat. Yogyakmta: PT. Tiara Wacana Yogya.

Departemen Agama RL (1993). AI-Qur'an dan Terjemahnya. Surabaya: Surya Cipta Aksara.

Eliade, Mircea (Ed.). (1993). The Encyclopedia of Religion. New York: Simon dan Schuster Mac Millan.

Ensiklopedi Nasional Indonesia (jilid II \}. (1990). Jakarta: PT. Cipta. Adi Pustaka.

Hammersma, Harry. (1992). Tokoh-tokoh Filsafat Barat Modern. Jakarta: PT. Gramedia Pustaka Utama.

Hassan, Fuad. (1992). Berkenalan dengan Eksistensialisme. Jakarta: Pustaka Jaya. 
Hastings, James (ed) (1983). Encyclopedia of Religion and Ethics. New York: Charles Seribner's Sons.

Hadiwijono, Harun. (1997). Sari Sejarah Filsafat Barat 2. Yogyakarta: Kanisius.

Ibn `Arabi, Muhyi al-Din (1980). Fusus al-Hikam. Beirut: Dar al-Kitab al-`Arabi

Ibn `Arabi, Muhyi al-Din. al-Futuhat al-Makkiyyah. Beirut: Dar al-Fikr.

Ibn `Arabi, Muhyi al-Din. Sufi-Sufi Andalusia. Bandung: Mizan.

Imam Muslim, (1992). Sahih Mustim IV. Beirut: Dar al-Kitab al-'Ilmiyyah.

Kattsoff, Louis O. Pengantar Filsafat. Yogyakarta: Tiara Wacana Yogya.

Muthahhari, Mwtadha. IVlanusta Sempurna: Pandangan Isiam tentang Hakekat Manusia. 3akarta: Lentera.

Nashr, Sayyed Hosseia. Menjelajah dunia modem: Bimbingan untuk kaum muda muslim. Bandung: Mizan.

Nietzsche, Friedrich tanpa tahun. Ecce Homo: Lthatlah Dia. Diterjemahkan oleh Omi Intan Naomi. 1998. Yogyakarta: Pustaka Pelajar.

Nietzsche, Friedrich. (1885). ?'hus Spoke Zarathustra: a Book for everyone and no one. Harmondsworth: Penguin Books.

Noer, Kautsar Azhari. (1995). Ibn al- Arabi: ma4dat al-weijud dalam perdebatan. Jakmta: Paramadina.

SChlRiiliei, Aweuiarie. (1997). lvfystical Dimensions o,f'Islam. Chapel Hill: The University of North Carolina.

Sharif, MK (ed). (1995). AHistory o,f Mus11m Philosopy. Delhi: Low Price Publications.

Solomon, Robert C. (1985). From Rationalism to Existentialism: the Exrtentialist and their ATneteenth-Century Backgrounds. Texas: University Press of America Inc.

Sunardi, St. (1996). N'retzsche. Yogyakatta: LKiS.

Suseno, Franz Magnis. (1997). 13 Tokoh Etika Sejak Jaman Yunani sampai Abad ke-I9. Yogyakarta: Kanisius.

Sutrisno, Mudji FX dan Hardiman B (eds.). (1992). Para Filsuf Penentu Gerak Jaman. Yogyakarta: Kanisius.

Takeshita, Masataka. (1987). Ibn 'Arabi's Theory of Perfect Man and its Place in the History of Islamic Thought. Tokyo: The Institute for the Study of Language and Culture of Asia and Africa. 